\title{
From Rubbish to a Large Scale Industry: A Simple Fabrication of Superfiber with Multitasking Applications
}

\author{
Hendry Izaac Elim (Elim Heaven) ${ }^{1,2}$, Ronaldo Talapessy ${ }^{1,2}$, Rafael Martinus Osok ${ }^{1}$, Sawia ${ }^{1,2}$ and Eliyas Andreas ${ }^{1,2}$ \\ 1. Nanotechnology Research Center and Creative Innovation (PPNRI-LEMLIT), Pattimura University, Poka Ambon 97233 , \\ Indonesia \\ 2. Nanomaterials for Photonics Nanotechnology Laboratory (Lab. N4PN), Physics Department, Faculty of Mathematics and Natural \\ Sciences, Pattimura University, Poka Ambon 97233, Indonesia
}

\begin{abstract}
In the whole earth, people increased dramatically from generation to generation which had created a large scale of broken environment so that people are facing more various types of garbage. Most of garbages are not useful and as a matter of fact, they are used to be neglected. Furthermore, many efforts have been conducted to change it by many types of recycled methods. Here, a simple technique is proposed with and without using fires to transform the useless natural or man-made rubbish things to be a superfiber as well as thin film with multitasking applications in human daily life. Since most of earth environment is covered by oceans, here the authors show how the ocean related garbage such as the crab skins, broken coral reefs and beach stones were changed to be superfiber and a multitasking device prototype.
\end{abstract}

Key words: Rubbish, fabrication, superfiber, multitasking, marine environment.

\section{Introduction}

Creating something novel always needs creativity as an ability to make an excellent product as well as an accurate knowledge as a background to transform a useless thing to be the most attractive product or prototype with a multitasking application [1-5]. In this paper, the authors propose a very simple technique by employing fire and without the use of fire to change various type of ocean garbage such as crab skins, broken coral reefs and useless beach stones to be superfibers and thin films with a proposed multitasking prototype product. The chosen few types of ocean garbage is just an example of the methods with the background that earth planet is majority consisted of ocean environment. For instant in Indonesia, it is about $70 \%$ of the whole country. Moreover, the Pacific ocean area is already about $46 \%$ of the earth ocean. While the Indian ocean is about

Corresponding author: Hendry Izaac Elim (Elim Heaven), Ph.D., main research fileds: intelligent nanomaterials and its multitasking applications.
$20 \%$. This ocean covered about $60 \%$ of the earth, can easily absorb the radiated rays from the outer earth as well as from some parts of the dark energies with a non-radiative power of unidentified dark matter objects. These complicated interaction things can create the roaring of oceans on earth with a significant global warming effect from the core of the ocean's bottom, surrounding by liquid fires on surface with the earth magnetic fields. In addition, the external radiative and non-radiative energy will go through ocean and have destination at the bottom of it. Because of this external bright (radiative) and dark (non-radiative) energy transfer, more power and higher inner temperature of the earth core can cause a broken earth.

In this paper, the authors tried to solve a part of broken earth particularly from the ocean garbage. The proposed simple technique with and without using fires to directly transform the useless natural or man-made rubbish things had produced a superfiber as well as thin film with multitasking applications in human daily life. Here as an example, the crab skins, 
broken coral reefs and beach stones were changed to be superfiber and a multitasking prototype product by using the above mentioned techniques.

\section{Experimental Methods and Techniques}

In order to fabricate a novel superfiber, the authors introduce two types of methods. The first one is employing fire to change a certain natural garbage material $[6,7]$. Another one is without the cooperation of the use of fire. The later was done to change the structure of the marine garbage materials to be a kind of novel 2D structure with a certain excellent optical and mechanical behavior.

Fig. 1 depicts the technique to transform marine garbage materials to be a superfiber without the use of fire $[6,7]$.

In Fig. 1, the first step is a waste step preparation. In this preliminary step, the authors take the wastes such as crab skins, broken coral reefs and beach stones, then clean them just with tape water so that the original part of it is not etched. Secondly, the peeling technique of the outer part of the garbage was conducted by scratching it in a rough paper. In this step, the atoms from the garbage will be sitting on the surface of the rough paper like a thin layer of flake. Third step is the use of a polymer tape to stick the atoms flake/layer on it in order to separate the rough paper from the atoms. Finally, the sticking atomic flakes on the tape are put on an etching liquid such as aseton in order to remove the polymer type tape.

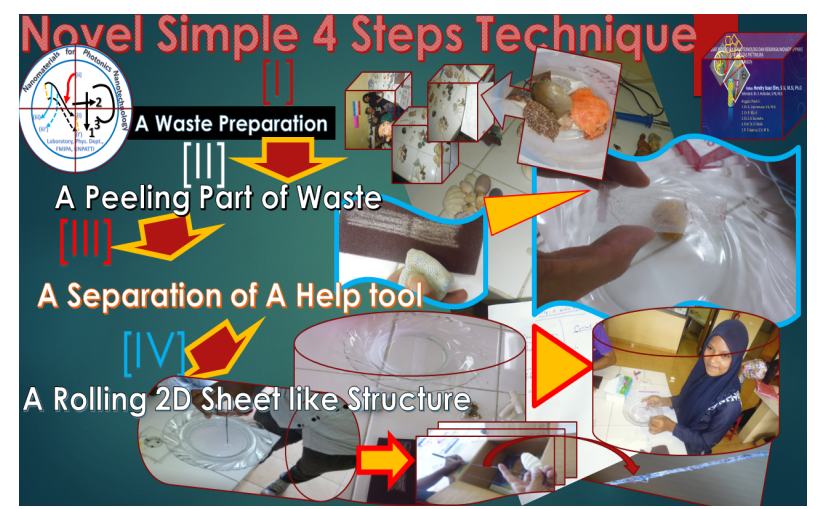

Fig. 1 Four steps technique to change and transform a marine garbage material to be a superfiber as well as thin film without the use of fire.

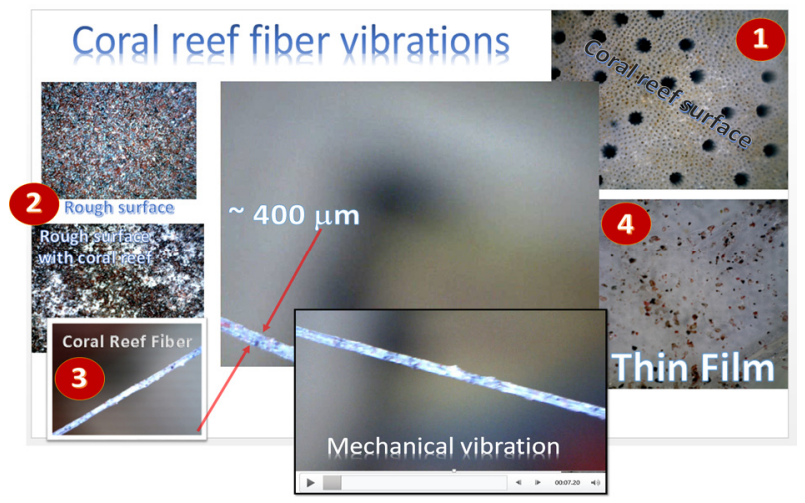

Fig. 2 An example of the use of 4 steps technique in Fig. 1, in this example, the authors changed a broken coral reef to be a superfiber with a very good mechanical properties and its thin film with a good optical property.

Fig. 2 shows one example of the final step of fiber and thin film by employing this simple technique.

In Fig. 2, the fabrication process of a superfiber and thin film made from a part of garbage is briefly shown. Furthermore, the vibration properties of such superfiber were observed and learned under an USB microscope connected to a computer.

\section{Technology of Multitasking Superfiber}

It is hard to do a simple technology for creating a multitasking product in a large scale. Here, the authors propose a simple technique to do that with the output fabricated superfibers from marine garbage. Fig. 3 shows how a simple device was built to measure the speed of sound of the fabricated fibers under the room temperature up to $70{ }^{\circ} \mathrm{C}$.

In order to make a real multitasking product from the fabricated superfibers, further works are necessary to be carried out by investigating the optical and mechanical properties of these superfibers. Moreover, this simple technology has to incorporate many types of superfibers with different characters fabricated from the marine garbage materials and another wastes materials. Fig. 4 shows how a suggested future work closely related to these multitasking products based on superfibers is prepared. Based on the results of mechanical behaviour of superfiber, such superfiber can be prolonged elastically about seven times without any broken part. 


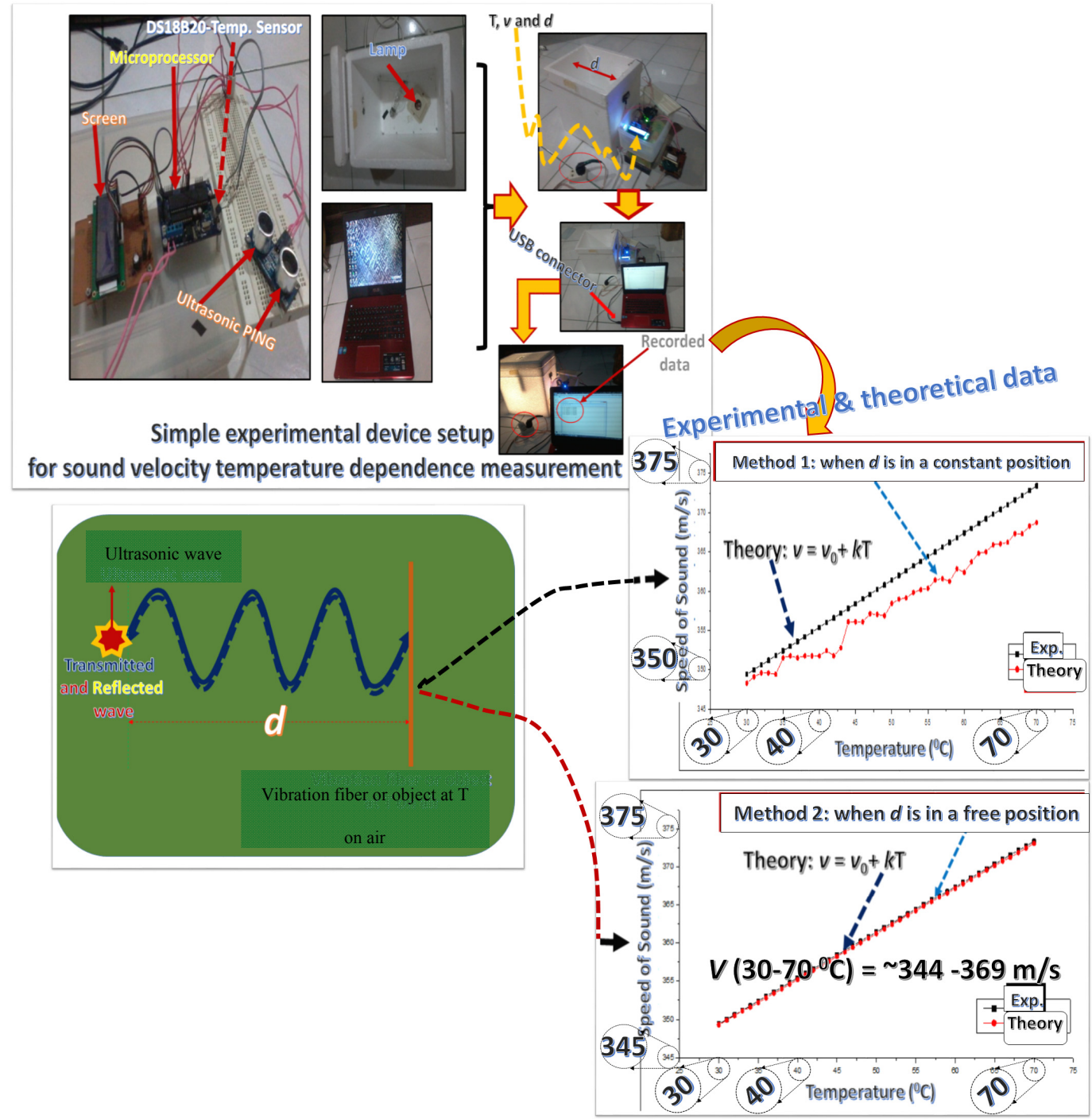

Fig. 3 Simple device fabricated to measure the sound velocity under the influence of room temperature ahout $30{ }^{\circ} \mathrm{C}$ up to $70{ }^{\circ} \mathrm{C}$.

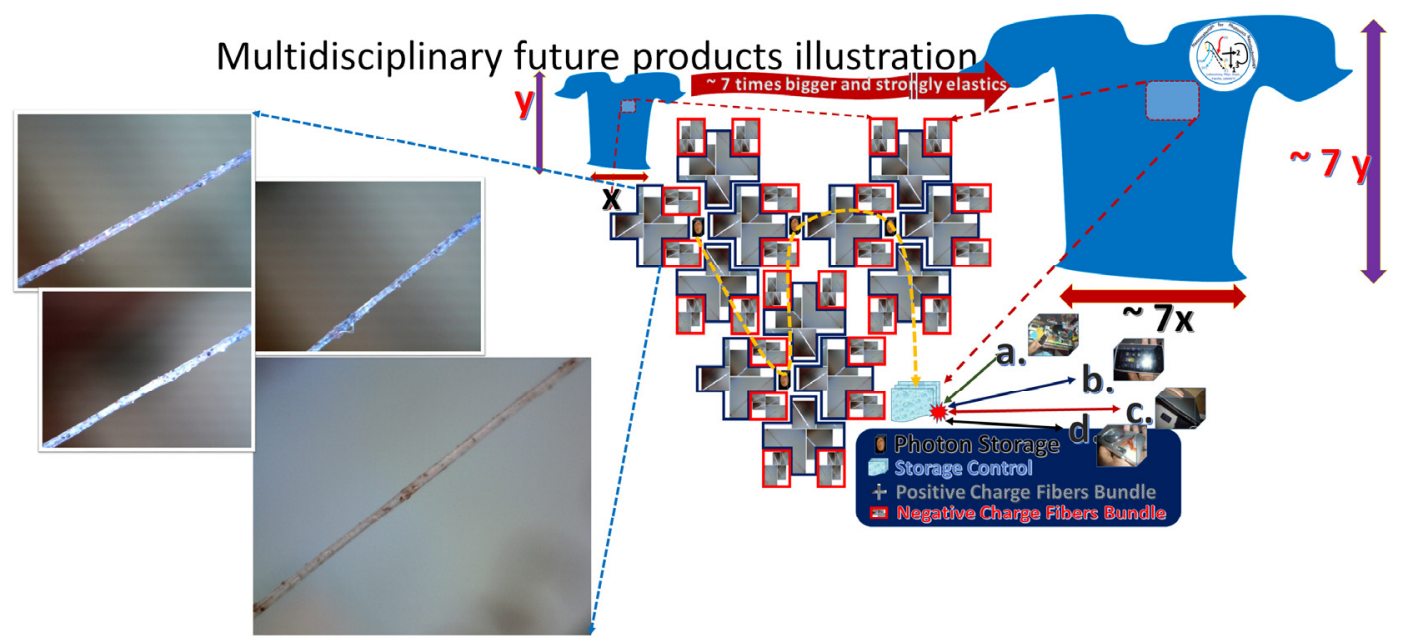

Fig. 4 Proposed multitasking product based on superfibers made by rubbish materials [7]. 


\section{Economic Implications of Multitasking Products}

While the numbers of cheap products with an international standard quality are being increased worldwide [8], view novel techniques have not developed very well yet particularly with low cost with a large scale products. It should be pointed out that by the use of these method and fabrication techniques, a cheap multitasking product in a large scale can be produced. The first thing is that the row materials are already invaluable due to the unused rubbish. The next thing is that the tools and the fabricated equipment are very simple, easily operated with a very low cost, and comfortable carried. Therefore, this technology can be conducted by any types of people without a special educational and social background in society.

\section{Summary}

In conclusion, it has shown that a novel simple technique can be used to fabricate a prototype superfiber from various types of marine garbage. A multitasking product with a large scale can be realized with a low cost and simple process and transformation. In addition, the broken environment on earth can be changed with a very high value for the development of people economic life.

\section{Acknowledgement}

The authors, especially Hendry Izaac Elim, Ronaldo Talapessy and Rafael Martinus Osok would like to give thank for the research grant support from "Riset Unggulan Daerah Maluku, Indonesia" with grant no. 1039/UN13/SK/2015.

\section{References}

[1] Kickelbick, G. 2007. Hybrid Materials, Synthesis, Characterization and Applications. Weinheim: Wiley-VCH.

[2] Althues, H., Henle, J., and Kaskel, S. 2007. "Functional Inorganic Nanofillers for Transparent Polymers." Chem. Soc. Rev. 36: 1454-1465. doi:10.1039/B608177K.

[3] Zimmermann, L., Weibel, M., Caseri, W., and Suter, U. W. 1993. "High Refractive Index Films of Polymer Nanocomposites." J. Mater. Res. 8: 1742-1748. doi:10.1557/JMR.1993.1742.

[4] Hendry Izaac Elim, Cai, B., Sugihara, O., Kaino, T., and Adschiri, T. 2011. "Rayleigh Scattering Study and Particle Density Determination of a High Refractive Index $\mathrm{TiO}_{2}$ Nanohybrid Polymer." Phys. Chem. 13: 4470. doi:10.1039/C0CP02052D.

[5] Hendry Izaac Elim, Cai, B., Kurata, Y., Sugihara, O., Kaino, T., and Adschiri, T. et al. 2009. "Refractive Index Control and Rayleigh Scattering Properties of Transparent $\mathrm{TiO}_{2}$ Nanohybrid Polymer." J. Phys. Chem. $B$ 113: 10143-10148. doi:10.1021/jp902598f.

[6] Hendry Izaac Elim. 2015. "Fabrication of Novel Fibers from Rejected Ocean Materials and Their Potential Applications." In International Proceeding of 1 st International Seminar of Basic Science, 21-27.

[7] Hendry Izaac Elim. 2015. "Simple Technology to Develop Marine Wastes: From a Prototype to a Large Scale Industry." In International Proceeding of 1 st International Conference on Applied Marine Science and Fisheries Technology (MSFT), 40-45.

[8] Ghosh, M., and Raychaudhuri, A. K. 2011. "Electric Field Induced Reversible Control of Visible Photoluminescence from ZnO Nanoparticles." Appl. Phys. Lett. 98: 153109-153111. 